\title{
Evaluation of the Risk Factors on Coal Dust Explosion in Warehouse
}

\author{
Latana Chanthaphasouk $^{1}$, Kreangkrai Maneeintr ${ }^{1}$, Pinyo Meechumna ${ }^{1}$, Suteera Luengwattanapong ${ }^{1}$, Chantamanee \\ Poonjarernsilp ${ }^{2}$ \\ ${ }^{1}$ Carbon Capture, Storage and Utilization Research Laboratory Department of Mining and Petroleum Engineering, Faculty of Engineering, \\ Chulalongkorn University, 10330 Bangkok. Thailand \\ ${ }^{2}$ Department of Chemical Engineering, Faculty of Engineering, Rajamangala University of Technology Krungthep, Bangkok 10120, Thailand
}

\begin{abstract}
Coal has been one of the major energy sources in the world. Many industries use coal as a main fuel. A coal dust explosion is one of the main hazards of coal utilization because of its massive damage. Coal dust explosion hazards involve the combustible fine dusts or other small particles that present a fire or deflagration hazard when suspended at a sufficient concentration in air or some other oxidizing medium. When such materials are contained in an enclosure, they present an explosion hazard. To eliminate the possibility of dust explosions by ensuring that the dust concentration does not exceed the minimum explosibility concentration (MEC) or the amount of dust per unit volume of air below which the dust cloud cannot propagate flame. Therefore, the objective of this work is to measure the MEC for coal dust explosion with the various conditions of coal storage such as the particle size, moisture of coal, degree of dispersion and delayed time of ignition source to prevent the coal dust explosion which aims to study and design the explosion safety measures for coal dust handing installations. The results show that smaller size of particle, low moisture in coal and high coal dust dispersion can increase the chance or risk of dust explosion. Also, the shorter time of dust dispersion exposes to ignition source can enhance the possibility of explosion in coal storage.
\end{abstract}

\section{Introduction}

Coal has been one of the major energy sources in the world. Many industries such as power plants, cement industries, pulp and paper industries use coal as a main fuel. However, there are many concerns about the environmental and safety issues. A coal dust explosion is one of the main hazards of coal utilization because of its massive damage. These hazards are recognized for the coal mines and coal processing plants. There are a number of scientific work aimed to reduce the coal dust explosion hazards in coal mines during the last century [1]. Moreover, dust explosion can occur in many industries including agriculture, food product, chemical, textiles [1]. It can happen within thermal dryer, cyclones, bag house, pulverizing fuel system, grinding mill and belt conveyor equipment [1], [2]. A dust explosion can cause of death and injuries and make the company waste of investment with combustible dust incident [3]. Dust explosion hazards involve the combustible fine dusts or other small particles that present a fire or deflagration hazard when suspended at a sufficient concentration in air or some other oxidizing medium. When such materials are contained in an enclosure, they present an explosion hazard [1], [3].

The explosions are caused by the combustion of materials. Particle properties as a fuel in the presence of adequate oxygen. Also, combustible dust in industry often pile up as dust layer or suspended as dust could otherwise the layer of dust was easy to induce fire and dust explosion often was convinced by dust could [4], [5].
The fire is ignited at a high enough energy. Moreover, in confined spaces or enclosed materials to the combustion, particles can be suspended or dust in the air for long enough [3]. There are a variety of size of particles that are burned up and dispersed. The explosion theory is based on the explosion of dust, which is called the theory of dust explosion pentagon consisting of fuel (dust), dispersion of dust, confinement, ignition source, and oxygen or air as shown in Fig. 1 [5], [6].

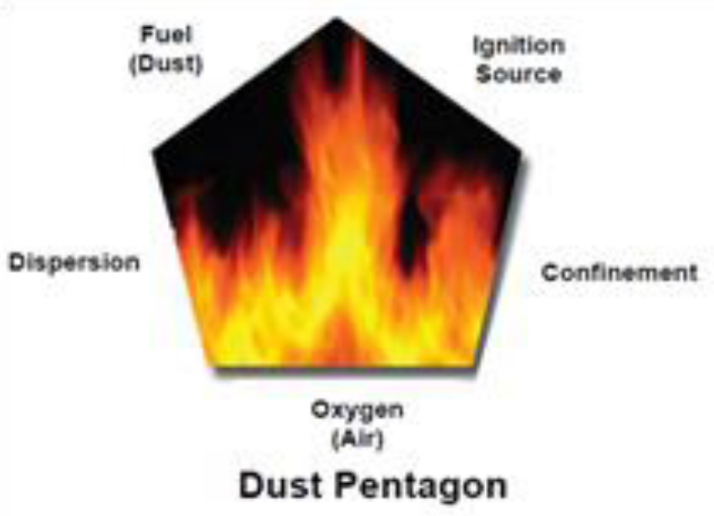

Figure 1. The pentagon of dust explosion [5], [6].

For a given type of explosible dust, particles are dispersed as a dust cloud in air. There is a minimum quantity of dust per unit volume of air below which the dust cloud cannot propagate flame. From the theory, one could eliminate the possibility of dust explosions by ensuring that the dust concentration does not exceed this 
minimum limit which is called the minimum explosibility concentration (MEC) which can be calculated by mass of particles divided by volume of the area for explosion. These amount of particles causing the explosion are usually determined with laboratory scale apparatus [7][9]. Tanthapanichakoon et al [9] calibrate the MEC equipment with lycopodium and compare the results with literature [10] and the results present that MEC of lycopodium is ranging from $47-50 \mathrm{~g} / \mathrm{m} 3$ comparing with literature [10] at $45 \pm 5 \mathrm{~g} / \mathrm{m} 3$. Furthermore, other materials such as wheat starch, polymer, toner and so on are tested for MEC. Moreover Man and Harris [3] has studied the addition of rock dust such as limestone to inert the coal dust explosion.

Therefore, the objective of this work is to measure the MEC for coal dust explosion with the various conditions of coal storage such as the particle size, moisture of coal, degree of dispersion and delayed time of ignition source to prevent the coal dust explosion. Also, this research investigates the explosion characteristics of coal dust which is undertaken as a part of the research at Chulalongkorn University, Thailand, which aims to study and design the explosion safety measures for coal dust handing process in the coal storage.

\section{Experiment}

\subsection{Material}

Coal dust for this study is obtained from the coal storage of Siam Cement Group Company. The size distribution of this dust is ranging from less than 45 micron to 53 micron.

\subsection{Equipment}

The experiment of dust explosion are conducted in $0.012297 \mathrm{~cm}^{3}$ volume of stainless steel tester chamber connected with air tank to supply air for gas dispersion with the pressure up to $50 \mathrm{psi}$ or $3.5 \mathrm{~kg} / \mathrm{cm}^{2}$. A 4 litter air compressor used for this study are compressor model OL1204 with the maximum of compressed air at 8 bar from Scientific Company Limited to feed compressed air to the tank. The high precision scale to measure the amount of coal dust comes from the OHAUS Company model PA214C with readability of 0.0001 digits and the operating conditions from $10 \mathrm{c}$ to $40{ }^{\circ} \mathrm{C}$ at $10 \%$ to $80 \%$ relative humidity. Sieve analysis model STS-S 414 from Soil Testing Siam Co. Ltd., is used to characterize and separate coal dust with different size from less than 45 micron to 250 micron. The moisture content is measured by using a moisture meter model MC7825PS with digital display indicating the moisture condition of the material. Specification of display is 4 digits, $10 \mathrm{~mm}$ LED with measurement ranging $0 \%$ to $80 \%$, and $\pm 0.5 \%$ accuracy. The operating conditions are $0-50{ }^{\circ} \mathrm{C}$ of the temperature and humidity below 90\% RH. Also, oven used to control the moisture of coal dust or sample derives from Memmert with maximum temperature at $200{ }^{\circ} \mathrm{C}$. This oven is operated at more than $100^{\circ} \mathrm{C}$ for this study.

\subsection{Experimental procedure}

Experimental procedure to obtain the MEC is described as follow. First humid coal dust sample is dried in the oven to control the humidity to the desired moisture. The known quantity of coal dust is measured and placed at the bottom of the dispersion nozzle. Coal dust is dispersed by compressed air and ignited by the high-voltage electric sparking [9]. Coal dust can be exploded or burned. The tests are performed 3 times with the same conditions to ensure that the results are correct.

The operating conditions for this study are presented in Table 1.

Table 1. Experimental operating conditions for this study.

\begin{tabular}{|l|l|}
\hline Parameter & Value \\
\hline $\begin{array}{l}\text { Particle size } \\
\text { (micron) }\end{array}$ & $\begin{array}{l}\text { Less than } 45,45, \\
\text { and } 53\end{array}$ \\
\hline Coal humidity $(\%)$ & $0,3,6,9$ and 12 \\
\hline $\begin{array}{l}\text { Pressure of air } \\
\left(\mathrm{kg} / \mathrm{cm}^{2}\right)\end{array}$ & $0.5,1$, and 1.8 \\
\hline Time $(\mathrm{s})$ & $0.1,0.3$, and 0.5 \\
\hline
\end{tabular}

\section{Results and discussion}

\subsection{Verification of equipment and procedure}

The apparatus and procedure are verified and compared by using lycopodium powder with the size of $32 \mu \mathrm{m}$, $35 \%$ to $45 \%$ humidity [9]. The MEC of lycopodium is obtained as shown in Figure 2 which is getting along well with the previous work with $4.9 \%$ deviation [6], [9]. Therefore, this equipment and procedure are good enough to further study. The experimental data for verify of equipment with lycopodium powder as show blow:

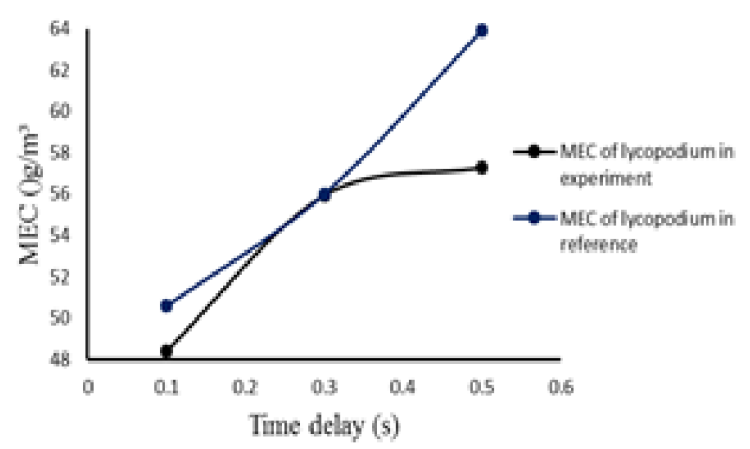

Figure 2. Verification of calibration MEC with lycopodium

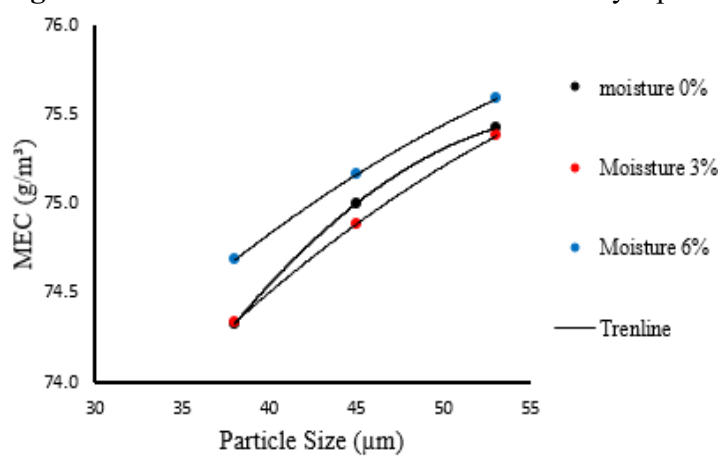

Figure 3 The effect of particle size, time $0.1 \mathrm{~s}$ compressor air $1.8 \mathrm{~kg} / \mathrm{cm} 2$ on MEC

\subsection{Effect of particle size on MEC}


The experimental results as shown in Fig. 3, indicate that particle size has effect on the amount of coal dust explosion or MEC in that MEC increases with particle size of coal dust. The smaller the particles, the higher chance to have coal dust explosion. Therefore, coal dust can be agglomerated to bigger size to reduce or prevent the explosion. From the experiment result the moisture content $0 \%$ and $6 \%$ and the percent of deviation is $0.48 \%$.

\subsection{Effect of coal humidity on MEC}

The effect of moisture content in coal is presented in Fig. 4. From the figure, it is obvious that coal humidity has less effect on MEC measurement. However, in term of ignition, humidity in coal is the key factor for coal explosion because in many cases, coal is burned but not exploded. Therefore, with higher moisture content in coal, the risk for coal dust explosion is reduced.

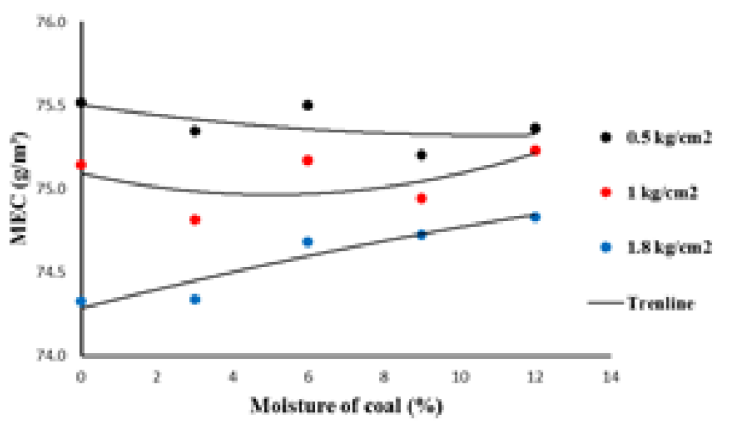

Figure 4. The effect of moisture in coal and air pressure, particle size less than 45 micron, $0.1 \mathrm{~s}$ on MEC.

\subsection{Effect of types of air pressure on MEC}

Air pressure reflects the degree of dispersion of coal in the confined space. If pressure of air injection is higher, the coal dust will be dispersed more. The results as shown in Fig. 4 indicate that at higher pressure, MEC will be lower. That means higher risk for coal dust explosion.

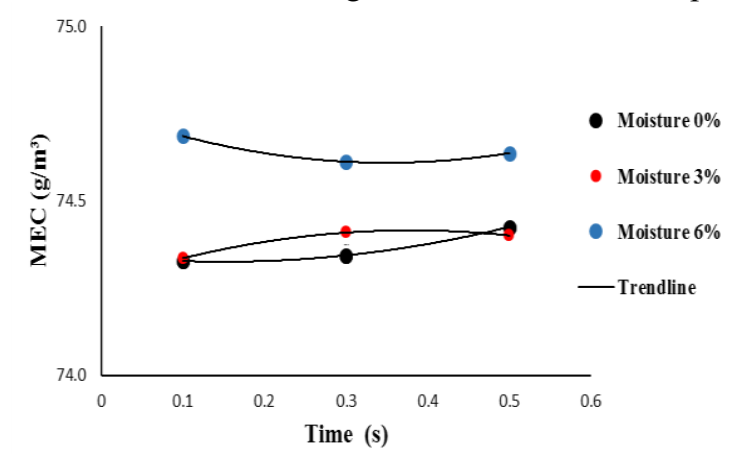

Figure 5. The effect of delayed time, particle size than 45 micron $1.8 \mathrm{~kg} / \mathrm{cm}^{2}$ for ignition on MEC

\subsection{Effect of delayed time on MEC}

The delayed time for sparking or ignition is the parameter to investigate the explosion. Less delayed time can increase the chance for coal to ignite thus increasing the risk for coal dust explosion. For this study, the effect of time as presented in Fig. 5. has less effect to measure
MEC. However, more delayed time will make less dispersion of coal because coal dust will drop down and the concentration of coal in the air becomes low. Then the ignition sources will start ignition with low concentration of dust. Therefore, there is less chance of dust to get ignited.

\section{Summary}

Coal dust explosion can cause lots of damage. To avoid this, the amount or concentration of coal dust per unit volume or MEC is measured with the various conditions of coal storage such as the particle size, moisture of coal, degree of dispersion and delayed time of ignition source to prevent the coal dust explosion which aims to study and design the explosion safety measures for coal dust handing installations. The results present that moisture content in coal has more effect on dust explosion. The smaller size of particle, low moisture in coal and high coal dust dispersion can increase the possibility or risk of dust explosion. Also, the shorter time of dust dispersion exposed to ignition source can enhance relatively low the possibility of coal dust explosion.

\section{Acknowledgement}

The authors would like to acknowledge the ASEAN University Network/Southeast Asia Engineering Education Development Network (AUN/SEED-Net) for financial support of this research. Secondly, the author would like to thank Graduate School Thesis Grant and Chulalongkorn University to accommodate for research periods. Also, the authors would like to thank Siam Cement Group (SCG) for coal dust sample. Lastly many thanks to the research students from Rajamangala University of Technology Krungthep for helping the experiment.

\section{References}

1. R.K. Eckhoff: Dust Explosion in the Process Industries, 3rd edition, Gulf Professional Publishing (2003).

2. S.R. George: The Explosibility of Coal Dust, Washington, Government printing office, (1911).

3. C.K. Man and M.L. Harris: submitted to Journal of Loss Prevention in the Process Industries, 27, (2014).

4. Y. Chunmiao, L. Chang, L. Gang: Coal dust explosion prevention and protection based on inherent safety, (2011).

5. F. Norman, J. Berghmans, and F. Verplaetsen: The minimum ignition energy of coal dust in an oxygen enriched atmosphere, (2013).

6. W. Tanthapanichakoon, V. Chongvisal, T. Charinpanitkul and V. Taepaisitphongse: Dust Explosive Limit Tester, Department of Chemical Engineering, Graduate School, Chulalongkorn University, (1996).

7. Information on http://www.nfpa.org 
8. M. Mittal: submitted to International Journal of Advanced Engineering Technology, (2003).

9. ASTM designation E1515 - 07. Standard test method for Minimum Explosible Concentration of Combustible Dusts, (2007).
10. APPIE. Standard/APS-001. Dust explosion Relief Venting for bag Filters, The Association of powder Process Industry and Engineering, Kyoto, Japan, (1983). 